\title{
Research and Discussion on the Development of Theory and Practice in \\ Environment Accounting
}

\author{
Zhao Li \\ Xizang Minzu University Xianyang, Shaanxi, 712082
}

\begin{abstract}
Keywords: environment accounting; enterprise; basic theoretical structure; environmental cost processing
\end{abstract}

\begin{abstract}
Environment accounting is an emerging product of China's enterprise economy in recent years. It is accompanied by global environmental problems, resource problems and the increasing environmental problems of enterprises. In such an environment, the enterprise must enhance the demand for environmental information combined with their own interests, thus to maintain normal and healthy production and business behavior, avoiding environmental risks as far as possible, making effective decisions conducive to management and production. Therefore, this paper is mainly to study a lot of elements involved in enterprise environment accounting in the construction of basic theory structure. Meanwhile, this paper is to deal with the practical operation technical process of enterprise environment accounting in the cost processing. On the one hand, the establishment of accounting is to co-ordinate the enterprise economy; on the other hand, it can also establish its assumed main body objectives and principles, forming its own basic theoretical system. As the an important branch of modern enterprise financial system, enterprise environment accounting should not only consider many aspects of impact brought by the enterprise economic activities, but also conduct the calculation of all environmental matters involved in enterprise, these accounting contents are classified and summarized into the accounting system.
\end{abstract}

\section{Interpretation of system elements of enterprise environment accounting theory}

The goal, hypothesis, object and principle are the four major elements in the traditional accounting system, and the theoretical system of enterprise environment accounting is analyzed one by one.

(A) Analysis of enterprise environment accounting goal

The enterprise environment accounting goal mainly includes two kinds: basic goal and specific target. First, the basic goal is to achieve the mutual harmonization of enterprise economic and social benefits. Considering that the traditional accounting focuses much on the achievement of single-goal decision-making under the economic efficiency, so when there's the growth period of socio-economy, the environmental problems will be exposed accordingly, bringing great pressure for social and economic development. In order to give more attention to enterprise environment transformation, the basic goal of environment accounting is focused on the economic benefit-oriented decision-making development to ensure mutual perfect coordination of economic and social benefits, achieving the sustainable development goal of the enterprise in the environment of social market economy.

Next is for specific goal. Enterprise environment will provide the enterprise with a wide range of sustainable development services, so there may be the existence of different environmental accounting information, users and information demand. Therefore, the theoretical development of environment accounting will also put forward a variety of requirements for its object. 
For enterprise investors, performance management of the enterprise environment accounting will affect enterprise's financial security and profitability. The investors are naturally very concerned about environmental performance of the enterprise, so the environment accounting must disclose this information.

For the enterprise creditors, specifically, banks, insurance finance enterprise put more emphasis on the protection of the social environment, and emergence of "green bank" is the evidence. In this regard, the creditor needs to understand the environmental risks assumed by the enterprise, on this basis to assess whether the enterprise has the debt-paying ability. Therefore, the environmental impact on the enterprise is not trivial, the time and extent of such impact will be concerned about by the enterprise creditors at any moment.

(B) Analysis of enterprise environment accounting hypothesis

Due to the changes of complexity and uncertainty of theory and practice involved in enterprise environment accounting, enterprise itself should make reasonable logical inference based on the understanding of environmental resources. This is the branch research field of the enterprise environment accounting---accounting hypothesis. Accounting hypothesis can be said considered as the integration of the traditional accounting hypothesis theory, and also an innovation, because it gives the accounting main-body new connotation from perspective of adhering to continuous management and accounting analysis. Taking the accounting principal hypothesis as an example, it requires the strict definition of the accounting object in terms of the position and spatial activities, so as to be clear about the main body. This is more conducive to the precise definition of enterprise environmental assets and liabilities and achieving the effective measurement of environmental benefits and environmental costs. If from a micro perspective, the enterprise environment accounting is the micro-organization used to achieve economic operation through development and use of environmental resources. The principal responsibility is not the single profit-making economic organizations, but it also should assume a certain social responsibility, and show as a unit of social development. Therefore, principal hypothesis of enterprise environment accounting should take full account of the environmental benefits of enterprise, and also actually reflect the organic combination results of enterprise in the economic and social benefits.

(C) Analysis of enterprise environment accounting object

The main object for the analysis of enterprise environment accounting includes the degradation of environmental resource value, natural resource and ecological resources. The corresponding enterprise production and management activities of the former can be conducted by the classification of ecological resources and natural resources, thus to ensure that the two kinds of resources are reasonably incorporated into the scope of environmental assets accounting. While the latter is based on the theory of environmental value, and the negative impact of the enterprise management on the enterprise can be clarified through calculation. Namely, it is the calculation of the consumption value of natural resources and environmental pollution losses. Considering that the two have a great impact on the environment, when the ecological resources are degraded, the value created by enterprise will drop sharply. Therefore, based on the external cost internalization theory, it is necessary to include the loss caused by the two above into the total cost of the enterprise, and into the scope of the environment accounting calculation appropriately.

According to the above content, enterprise environment accounting must also be divested from the traditional financial account for separate calculation, which is the difference between the environment accounting and traditional enterprise accounting. Enterprise environment accounting is relatively independent with its own accounting capacity. For example, the environmental expenditure accounting is to calculate the environment load produced by the enterprise products 
within the life cycle based on environmental responsibility, and the erosion of the environmental impact on its life and economic attributes. Therefore, environment accounting will inevitably include environmental management costs, environmental compensation costs, environmental prevention costs and environmental administrative costs of the enterprises.

(D) Analysis of enterprise environment accounting principle

Enterprise environmental accounting principles are becoming diversified development. For example, the social principle means that environment accounting must provide various kinds of information beyond enterprises based on the needs of social-related enterprises to consider enterprise performance, thus to achieve the final purpose of enterprise performance evaluation, ensuring the reasonable match between the social benefits and social costs. There's the principle of combined use of a variety of pricing bases, which takes full account of the specificity of environmental problems and measurement complexity. The pricing basis is conducted by starting from historical cost direction, and the current costs, replacement costs and opportunity costs and others subjected to enterprise environment accounting are used to reflect enterprise's environmental problems to be resolved.

The above four points together constitute the theoretical structure system foundation of enterprise environment accounting. It is precisely because of their existence and rational use that allow enterprise environment accounting to achieve information disclosure, cost management and other accounting behaviors, which offer the strong support for enterprises to solve environmental problems $^{[1]}$.

\section{Practical operation analysis in enterprise environment accounting----cost processing method}

Enterprise environment accounting covers a wide range of content, but it has only one core of enterprise environment cost, the core is directly related to the enterprise's economic and environmental problem-solving ability. Moreover, the environment cost is different from any traditional cost management content, and its calculation method is also very unique.

(A) Cost processing method of enterprise environment accounting

Life Cycled Costing (LCC) is the most common cost processing method in current enterprise environment accounting. It is mainly used to analyze the environmental influencing factors generated from product design and engineering design. From the processing perspective, LCC method covers four links: determination of the target, life cycle inventory, impact assessment and improved analysis.

If LCC method is viewed from an enterprise perspective, it should run through the entire life cycle of the product, including material processing, product design, production, warehousing, sales, as well as use and disposal. The internal and external environmental costs of this series of processes should be included into the whole process of environmental consumption accumulation. The environment cost should be classified based on this method, including mainly material energy and construction consumption-based conventional costs, the debt cost based on economic loss, life and property loss, public image loss and other losses, and also the environmental costs resulting from the formation of pollution due to the natural and man-made influences. In sum, compared to the conventional cost, environmental cost is the already incurred cost, and the data involved can be directly replaced into the product environment cost calculation. But for the debt cost without loss incurrence, the enterprise can predict its losses. The recovery cost, alternative evaluation can be used for calculation and estimation, thus to draw conclusions and build preventive measures.

(B) Environmental cost accounting system based on the total cost framework of enterprise 
Environmental cost is only a branch of the enterprise's total cost, in other words, environment accounting should also follow the theory of total cost of enterprise to understand the enterprise cost structure, calculating the environmental cost from the large framework. The following is the calculation of operating cost of the enterprise:

Enterprise's total cost =production cost + environment protection cost + environment damage cost

In the above formula, environment damage cost is the most difficult for calculation. For industrial enterprises, the environmental damage cost is the natural pollution of social consumption costs caused by the "three wastes", which includes the two major levels of natural resource depletion and ecological degradation. The difficulty of calculating environment damage costs is that these pollution factors are uncontrollable in terms of confirmation and measurement. However, if it is specific to an enterprise, the environmental damage cost range and nature caused accordingly can be fixed. As long as the calculation method is reasonable, the assessment of environment damage costs will be logical. Enterprise can complete the environmental assessment cost through organizing professional technical team, access to relevant information, field investigation, and the environment damage assessment can be completed with the help of environmental protection agencies. Finally is to calculate the environment damage cost by finding the appropriate measurement method for the enterprise. The specific measurement process of the enterprise environment damage cost is shown in Figure 1.

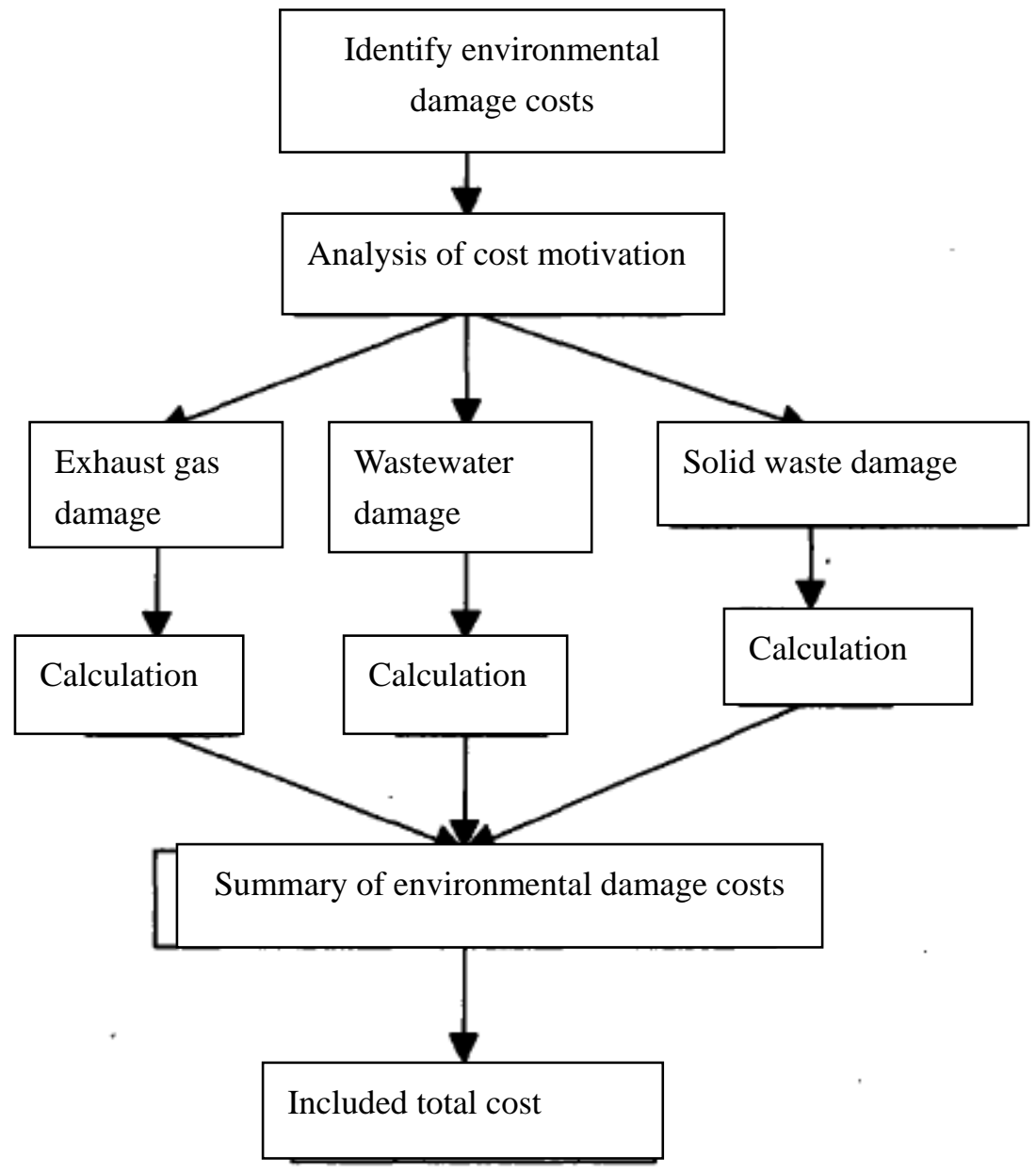

Figure 1 Calculation flow chart of enterprise environmental damage cost 
If there's the need to make reasonable use of the environment accounting system development practice, it's essential to establish the framework of total cost calculation, actively creating favorable conditions to promote the enterprise environment cost calculation, and strengthening construction of environmental cost accounting system. In addition, it's also necessary to create external conditions to improve understanding of environmental cost accounting, reducing the human barriers in the process of implementation to the largest extent. It's essential to identify that the environment cost accounting is not just a simple accounting problem, which also involves more interdisciplinary technologies. There's the need to integrate into a wide range of technical theory practical experience for the comprehensive consideration ${ }^{[2]}$.

\section{Empirical analysis}

By taking a resin chemical industry in Guangdong Province for example, it mainly produces rosin modified phenolic resin and rosin ester, with the annual production capacity of more than 6,000 tons. In 2015, the annual sales income of the industry was RMB30 million Yuan, and its profits reached RMB3.04 million Yuan. Since the enterprise belongs to a typical chemical production enterprise, its "three wastes" problem is very serious. Since 2014, the enterprise has used the biochemical oxidation treatment to control and deal with the industrial wastewater, pollution control effect is quite significant, the current environmental indicators are in line with requirements. This has brought a good positive influence for controlling the enterprise environment accounting cost and total cost.

By taking the environment damage cost accounting in the enterprise environment accounting system for an example, first is to identify that the external cost reason of the enterprise production pollution is the "three wastes" discharge. Therefore, when the wastewater treatment standard is reached the standards, external environment damage cost can be basically neglected. Therefore, the environment damage cost of the waste, dust and sulfur dioxide pollution caused from production process is calculated. This paper is mainly to assess the environment damage cost caused by the coal-fired coal dioxide emissions.

The total consumption of coal of the company in 2014 reached $7000000 \mathrm{~kg}$, and sulfur in the coal includes two parts of combustible sulfur and non-combustible sulfur. Most of the sulfur is present in the combustible coal, which is oxidized to produce sulfur dioxide into the flue gas when burning. It is calculated that the sulfur dioxide in combustible sulfur accounts for about $80 \%$, so sulfur dioxide emissions from the production can be calculated according to the sulfur oxidation conversion chemical calculation relation:

$$
\mathrm{Q}=2 \times 80 \% \times \mathrm{BxS}
$$

In the formula, B represents the total amount of coal consumption (kg), and $\mathrm{S}$ represents the total sulfur content in coal. According to the standard of average sulfur content of $1.2857 \%$ in the national coal industry of China's natural science research, the specific value of sulfur dioxide emissions can be calculated as $139000 \mathrm{~kg}$. At this point, the environment damage cost of sulfur dioxide can be calculated, sulfur dioxide treatment cost calculated by enterprise is 500 Yuan/ton, so the environmental damage costs of sulfur dioxide should be:

$$
\mathrm{C}=\mathrm{Q} \times 500=139000 \times 500 \times 10^{-3}=69500.00 \text { 元 }
$$

Based on the above environmental damage cost calculation results, the following treatment of the enterprise environment accounting can be conducted:

Debt: environment damage cost RMB69500.00 Yuan

Loan: environment reserve RMB69500.00 Yuan

After the enterprise predicts the environment damage cost caused by sulfur dioxide, the 
environment reserve should be proposed in advance. This is also to avoid the environment risk to the largest extent to solve environmental problem for enterprises to ensure stable development ${ }^{[3]}$.

\section{Summary}

The environment accounting research is very significant for development of China's enterprise, which has now drawn the extensive attention of the community and various enterprises. This paper only clarify the basic goals, objects, hypotheses and principles of development of enterprise environment accounting from theoretical principles of environmental accounting and cost management practice. The necessity of the enterprise environment damage cost accounting is discussed from the economic perspective, thus to hope to provide the necessary theoretical and technical reference basis for implementation and the development of environment accounting of China's enterprises in the future.

Acknowledgment

Project: the Tibet autonomous region higher education teaching reform project for 2015

Number: Jg2015-29

\section{References:}

[1] ya-lian zhang. The enterprise environment accounting basic theory and practice research [D]. Central south forestry college, 2014.41-46.

[2] de-ming kong. Our country enterprise environment accounting application research [D]. Southwest university of finance and economics, 2007.30.

[3] RaoZhiYing. Based on the concept of scientific development of the enterprise environment accounting study, township enterprises, for example [D]. Hunan agricultural university, 2012.10-20. 